unit equals the number of beds on the unit, if each patient is to receive one hour weekly of personal staff time.

Many doctors work in units where $\mathbf{N}$ is much greater than 10-20. In many acute day hospitals, for instance, the number of patients 'on the books' may be 40-80. One doctor working in such a unit simply cannot talk personally at any length with more than a small proportion of the patients. What often happens, of course, is that patients are 'talked to' by nondoctor members of the 'team'. So we could say that if every patient is to have access to a staff person for one hour a week, then the number of 'staff people hours' needed must equal the number of patients in the unit $(\mathrm{N})$. If it is usual for a full-time staff person to talk to patients for about fifteen hours weekly, then for thirty patients, two staff who can talk to patients are needed; for forty-five patients, three staff; for sixty, four; and so on. The number of doctors required in a unit obviously depends on what the doctor is to do, and also on the number of competent other professionals in the unit, and what they can do, and these must be known before the need for doctors can be estimated with confidence.

In some units, the value of $\mathrm{H}$ (total weekly 'talking to patients' time) exceeds $\mathrm{N}$ (number of patients in the unit). We found that in one forty-place day hospital, three doctors provided $\mathbf{4 8}$ hours for work with individual patients. The doctors were a consultant whose main locus of work this was, and a medical assistant and registrar based whole time at the day hospital. We did not study the extent to which the doctors might have been interchangeable or replaceable by non-doctors. Evidently, if one or more of the doctors is redeployed, then either nobody talks to the patients, or a non-doctor does it: up to a point this is true whether the 'redeployed' doctor is the consultant, a trainee, or a non-trainee junior. The disposition of trainees should be informed by knowledge of what non-trainees, as well as non-doctors, can do in the units concerned.

\section{A catchment area}

Finally, we will briefly consider how many doctors might be required to serve a catchment area of a defined size. A convenient starting point is Birley's $s^{4}$ estimate that a catchment of 60,000 might generate in one year 215-300 in-patient admissions, with a length of stay of five to seven weeks, and that in out-patients there would be five new patients weekly and thirty reviews. Birley suggested that forty day places would also be needed, but did not suggest the admission rate.

For this amount of in-patient work, approximately fifteen 'talking to patient' hours will be required weekly, if each of 250 acute in-patients is to be seen for two hours on admission and for one hour weekly for each of three post admission weeks. For five new out-patients each seen for one hour, and thirty review patients each seen for thirty minutes, twenty hours will be required.

So for acute in-patients and out-patients, approximately 35 hours of doctor time might be required, and on the basis of the figures given by Guy's trainees this might be provided by two trainees without other commitments. Additional doctors would be needed for any medical contribution to other timeconsuming catchment area service responsibilities, such as the care of long stay, day, and liaison patients and the assessment of or consultations about people at home or in community placements. It seems likely therefore that psychiatric (medical) staffing needs to be increased substantially if the service is actually to be based on what has traditionally been supposed to be its foundation, namely personal conversation between patients and doctors trying to help them. No doubt some of the 'talking to patients' which doctors might do in a psychiatric service can be done as well by non-doctors, but the circumstances in which this is true await systematic study. This would seem to be an urgent topic for research in view of the proliferation of plans for community teams of variable composition and unspecified levels of competence.

REFERENCES

IRUSSELL, G. F. M. (1973) Will there be enough psychiatrists to run the psychiatric service based on district general hospitals? In Policy for Action (eds R. Cawley and G. McLachlan). London: Nuffield Provincial Hospitals Trust and Oxford University Press.

2Resource Allocation Working Party (1976) Sharing Resources for Health in England (RAWP Report). London: HMSO.

3Social Services Committee (1981) Fourth Report: Medical Education with Special Reference to the Number of Doctors and the Career Structure in Hospitals (Short Report). London: HMSO.

${ }^{4 B i r l e y, ~ J . ~ L . ~ T . ~(1973) ~ T h e ~ g h o s t ~ i n ~ t h e ~ m a c h i n e . ~ I n ~ P o l i c y ~ f o r ~ A c t i o n ~}$ (eds. R. Cawley and G. McLachlan). London: Nuffield Provincial Hospitals Trust and Oxford University Press.

\title{
National Health Service Training Authority
}

Members might be interested to know that the National Health Service Training Authority is to produce a substantive document entitled An Outline for a National Training Strategy which should be available in the Autumn. If any members are interested in organizing Management Training Courses, then funds may be available from the NHSTA and enquiries should be made to Mr R. W. Deardon, Chief Executive, National Health Service Training Authority, St Bartholomew's Court, 18 Christmas Street, Bristol BS1 5BT.

Professor C. P. Seager Chairman, Working Party on Management Training
The following prizes have been awarded in 1985:

Gaskell Medal and Prize: Dr M. S. Keshavan, King's College Hospital, Denmark Hill, London SE5; Bronze Medal and Research Prize: Dr M. D. Kopelman, Institute of Psychiatry, De Crespigny Park, London SE5. 